DOI: https://doi.org/10.24867/03CG13Dakic

\title{
MATEMATIČKO MODELIRANJE OBARANJA NIVOA PODZEMNE VODE NA LOKACIJI GRADILIŠTA FUDBALSKE AKADEMIJE U BAČKOJ TOPOLI PRIMENOM SOFTVERSKOG PAKETA GMS
}

\section{MATHEMATICAL MODELING OF GROUNDWATER LEVEL REDUCTION AT THE CONSTRUCTION SITE OF THE FOOTBALL ACADEMY IN BAČKA TOPOLA USING THE GMS SOFTWARE PACKAGE}

\author{
Marijana Dakić, Ljubomir Budinski, Fakultet tehničkih nauka, Novi Sad
}

\begin{abstract}
Oblast - GRAĐEVINARSTVO
Kratak sadržaj - Za potrebe snižavanja nivoa podzemne vode na parceli gradilišta Fudbalske akademije u Bačkoj Topoli analizirano je rěsenje sa sistemom drenažnih bunara. Podzemnu vodu potrebno je spustiti na $1 \mathrm{~m}$ ispod površine terena kako bi se površinski slojevi tla drenirali, čime bi se omogućio pristup $i$ vršenje radova na gradilištu teškim građevinskim mašinama. Stanje podzemne vode $i$ efikasnost drenažnih bunara je modelisano $i$ analizirano primenom numeričkog modela na bazi konačnih razlika upotrebom softverskog paketa GMS (Groundwater Modeling System).
\end{abstract}

Ključne reči - Podzemne vode, bunari, numerika, modelovanje

Abstract - For the purpose of reducing the groundwater level at the construction site of the Football Academy in Backka Topola, the solution which includes groundwater control by drainage wells had been analyzed. Levels of groundwater needs to be decreased to at least $1 \mathrm{~m}$ below the terrain surface in order to drain the upper layers of the soil which will allow the access and the opportunity for heavy machinery to complete their part of the work. Groundwater flow and the efficiency of drainage wells has been modelled and analyzed by the means of a numerical model based on finite difference method using software package GMS (Groundwater Modeling System).

Keywords - Groundwater, wells, numerics, modeling

\section{UVOD}

Parcela gradilišta Fudbalske akademije nalazi se na severnom obodu Bačke Topole. Sa severne i zapadne strane oivičena je ulicama Plitvičkom i Krivajskom, sa južne strane graniči se sa privatnim posedom, dok istočnu granicu građevinskoj parceli predstavlja potok Krivaja. U radu je modelisana šira oblast strujanja podzemne vode kako bi se stekao uvid u njeno zatečeno stanje i u uticaj drenažnih bunara na nivo podzemne vode [2].

Pedološke i geološke karakteristike područja određene su na osnovu $[4,5,6]$.

\section{NAPOMENA:}

Ovaj rad proistekao je iz master rada čiji mentor je bio dr Ljubomir Budinski, vanr.prof.
U osnovi gledano modelisana oblast severno se prostire do akumulacionog jezera Zobnatica, dok sa istočne strane njenu granicu predstavlja potok Krivaja. Akumulacija visoke kote vodnog ogledala predstavlja izvor podzemne vode, a potok Krivaja svojom nižom kotom predstavlja prijemnik. Između ova dva vodna tela postavljena je veštačka granica sa linearnim spuštanjem pijezo kote od akumulacije ka potoku.

Za potrebe uspostavljanja ustaljenog, prostornog (3D) modela, preko posmatranog područja primenom softverskog paketa, korišćeni su ulazni parametri upotrebljeni u odgovarajućem ravanskom (2D) modelu rođenom u programu EXCEL, a koji je obuhvaćen drugim master radom.

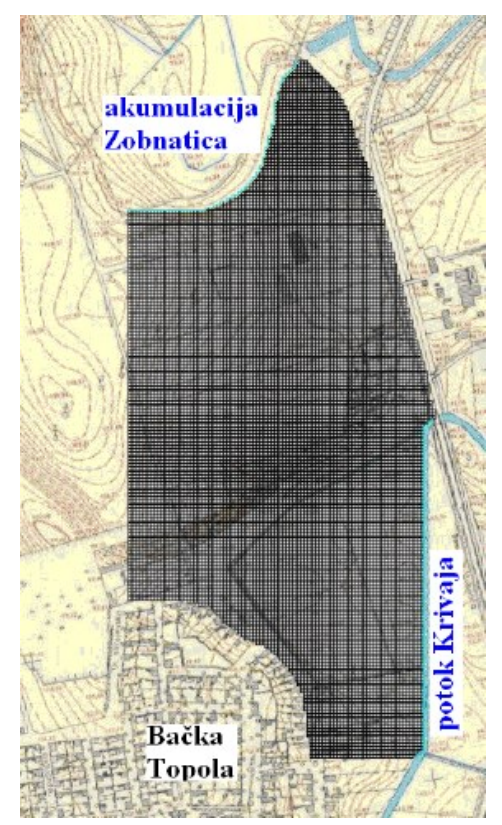

Slika 1. Računska mreža preko topografske karte

\section{NUMERIČKI MODELI}

\subsection{Modeliranje strujanja podzemne vode}

Model je predstava nekog stvarnog, fizičkog sistema i njegovih procesa. Pod modelom strujanja podrazumeva se sredstvo koje može da posluži za opis strujanja u nekom hidrogeološkom sistemu. Strujanje podzemne vode u nekom akviferu rezultat je međusobnog dejstva svih činilaca hidrogeološkog sistema (voda, akvifer, 
konturni uslovi). Model služi za prognoziranje reakcije akvifera na prirodne i ljudskim aktivnostima izazvane promene, a u kasnijoj fazi - nakon tariranja - može da služi za upravljanje vodnim resursom. Cilj izučavanja jeste, da se utvrdi pijezometarski nivo u proizvoljnoj tački akvifera, pored toga raspored brzina u strujnom polju [1].

Za rešavanje ovog zadatka korišćen je metod konačnih razlika upotrebom softverskog paketa GMS. U zadatom slučaju radi se o strujanju podzemne vode sa slobodnom površinom, a matematičkim modelom koji će se primeniti u ovom radu modeliše se ustaljeno, prostorno strujanje (u sva tri koordinatna pravca).

Koraci u rešavanju zadatka strujanja podzemne vode numeričkim postupkom su:

- utvrđivanje odgovarajuće diferencijalne jednačine strujanja,

- diskretizacija jednačine,

- postavljanje računske mreže u strujnoj oblasti od interesa,

- definisanje graničnih i početnih uslova,

- primena diskretizovanih jednačina na mrežu i

- rešavanje sistema algebarskih jednačina dobijenih primenom jednačine iz tačke 2 u čvorovima iz tačke 3 , za zadate granične uslove po tački 4 [3].

\subsection{Izbor računske oblasti i računske mreže}

Metoda konačnih razlika zahteva da se oblast strujanja diskretizuje, podeli kvadratnom ili pravougaonom (ortogonalnom) mrežom na prostorne, ravanske ili linijske kontrolne elemente.

U slučaju modela prostornog (3D) strujanja unutar diskretizovane strujne oblasti mrežom se formiraju kontrolne zapremine. Svakoj kontrolnoj zapremini pripada računska tačka u njenoj sredini.

Kod prostornog (3D) modela elementi mreže su kontrolne zapremine, kocke ili pravougaone prizme čije stranice imaju dužinu prostornog koraka $\Delta \mathrm{x} 1, \Delta \mathrm{x} 2, \Delta \mathrm{x} 3 \mathrm{u}$ pravcima odnosnih koordinatnih osa $\mathrm{x} 1, \mathrm{x} 2, \mathrm{x} 3$. Mrežom se formiraju kolone, redovi i slojevi, isto tako i čvorovi u strujnoj oblasti.

Nepoznate veličine od interesa određuju se računski u središtu ćelija (mreža kontrolnih zapremina).

\subsection{Definisanje graničnih uslova}

Svako izučavanje strujanja podzemne vode odnosi se na određenu prostornu oblast i vremenski period. Granične uslove čini skup poznatih pokazatelja po graničnim površinama oblasti izučavanja.

Razmatrani problem određuju granični uslovi poznate pijezo kote duž granica strujne oblasti:

- sa severne strane prirodnu granicu posmatrane oblasti čini akumulaciono jezero poznate pijezo kote:

$H=H_{\text {JEZERA }}$,

- sa istočne strane poznat nivo potoka Krivaja definiše drugu prirodnu granicu:

$H=H_{\text {KRIVAJE }}$,

- duž veštačke istočne i zapadne granice modelisane oblasti (između akumulacije i Krivaje ) kao granični uslov apliciran je linearno opadajući pijezo nivo između pomenuta dva vodna tela [2].

\section{USPOSTAVLJANJE MODELA STRUJANJA PRIMENOM SOFTVERA GMS}

U cilju realizacije zadatka master teze izvršeno je sledeće:

- za merodavno prirodno stanje uspostavljen je numerički 3D model za utvrđivanje strujne slike podzemne vode za homogenu sredinu uz upoređivanje rezultata sa ravanskim modelom u osnovi (2D);

- usvojeni način snižavanja podzemne vode sistemom bunara iz 2D modela implementiran je u 3D model uz upoređivanje dobijenih rezultata;

- izvršena je analiza rezultata različitih mreža u smislu rezolucije i progušćenja računske mreže u sva tri koordinatna prvaca na lokacijama bunara,;

- utvrđena je strujna slika modela sa 2 sloja različitog geološkog sastava za prirodno stanje i stanje usled primene odabrane mere snižavanja podzemnih voda;

- na osnovu dobijenih rezultata prethodnih analiza izvršena je revizija i korekcija projektovanog stanja bunara dobijenim primenom 2D modela.

\subsection{Uspostavljanje 3D numeričkog modela prirodnog stanja za homogenu sredinu}

Izvršena je analiza i komparacija dva modela (prvi za ravansko strujanje, a drugi za prostorno) sa identičnim ulaznim parametrima za postojeće stanje (stanje bez uspostavljanja odgovarajućeg sistema snižavanja podzemnih voda) za jednoslojnu sredinu. Računska mreža je definisana tako da što približnije odgovara mreži ravanskog modela sa ćelijama dimenzija $4 \times 4 \mathrm{~m}$.
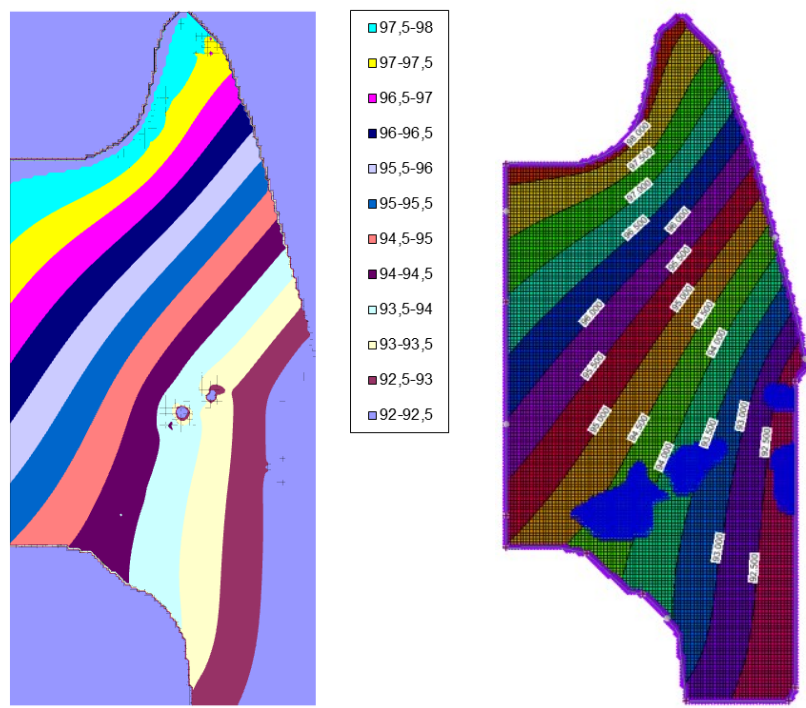

Slika 2. Prikaz nivoa podzemne vode za $2 D$ model [2] $i$ $3 D$ model

3.2. Uspostavljanje 3D numeričkog modela sa sistemom bunara za homogenu sredinu

U ovom koraku izvršeno je modeliranje sredine sa uvezenim bunarima koji koordinatno odgovaraju bunarima iz ravanskog modela sa definisanim nivoom.

I ovom analizom potvrđeno je da 3D model daje praktično identične rezultate kao $2 \mathrm{D}$ model za mrežu ćelija dimenzija $4 \mathrm{mx} 4 \mathrm{~m}$, što je ujedno i verifikacija 3D modela, odnosno potvrda ispravnosti samog GMS modela kao i da je kompletan model pravilno podešen. 


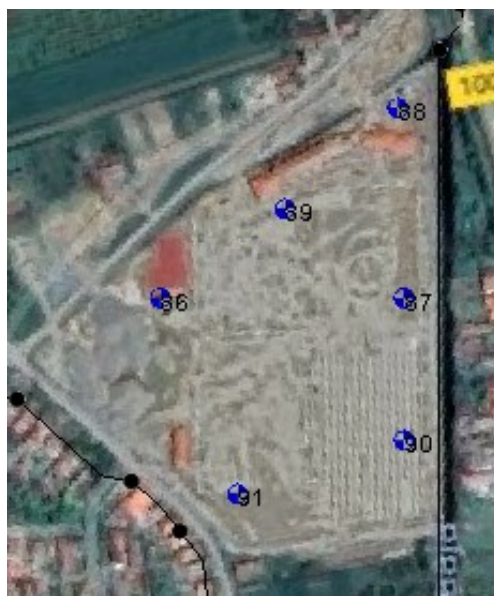

Slika 3. Raspored bunara na prostoru predviđenog gradilišta

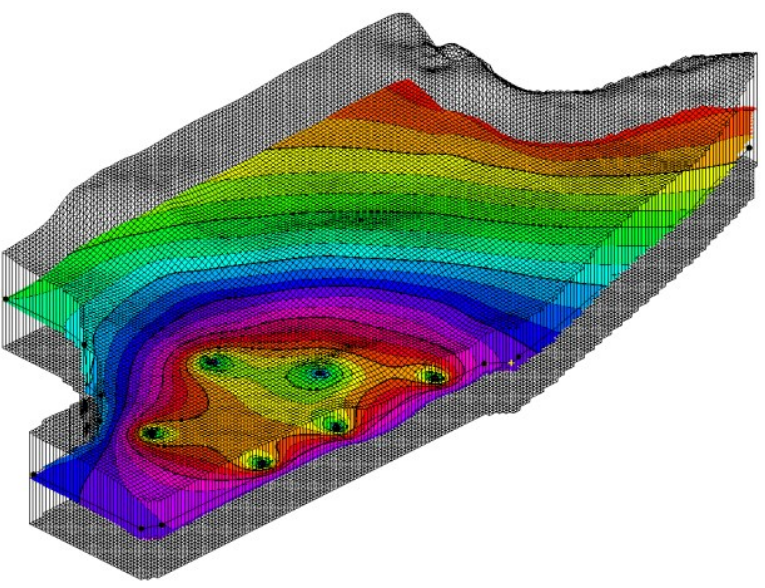

Slika 4. 3D prikaz modela za homogenu sredinu sa unetim sistemom bunara sa konstantnim nivoom (raster mreže $4 x 4 m$ )

\subsection{Uspostavljanje 3D numeričkog modela sa različitim konfiguracijama računske mreže}

Daljom analizom izvršeno je ispitivanje različitih konfiguracija mreže u smislu zadavanja različitih rastera računskih ćelija i njihovih uticaja na model. Nakon ove analize ispitivan je uticaj različitih rezolucija mreže odnosno progušćenja u zoni bunara gde su brzine filtracije najveće.

Sa smanjenjem dimenzija ćelija celokupne mreže opaženo je opadanje protoka sa jedne strane, i konstantna vrednost protoka za tri različite konfiguracije, a pri istim parametrima progušćenja mreže. Ukoliko se uzme jedna vrednost parametara progušćenja preostali deo mreže može se proizvoljno menjati, a da to ne utiče na protok u bunaru. Ovo znači da rezolucija preostale oblasti ne utiče na dobijene protoke, ali izbor parametara progušćenja značajno utiče. Analiza mreže pokazuje da je neophodno voditi računa o rezoluciji mreže u cilju dobijanja validnih rezultata. Što je veće obaranje veći su i nagibi linije nivoa pa je u cilju dobijanja kvalitetnih rezultata potrebno izvršiti progušćenje mreže oko bunara. Ako se pogledaju rezultati, primećuje se da kako se povećava rezolucija ne samo da protoci na bunarima opadaju, već i nivoi u preostaloj oblasti dodatno rastu odnosu na nivoe iz 2D modela. Za slučaj iste mreže sa progušćenjem dobija se veći nivo nego bez progušćenja.
Tabela 1. Poređenje dobijenih protoka na bunarima za razlicite parametre progušcenja

\begin{tabular}{|c|c|c|c|c|c|}
\hline \multicolumn{6}{|c|}{$\begin{array}{c}\text { Protok na bunarima za zadat konstantan nivo ( } 82 \mathrm{~m} . \mathrm{n} . \mathrm{m} \text {.) u zavisnosti od prugušćenja } \\
\text { računske mreže na lokacijama bunara (mreža } 4 \mathrm{M} \mathrm{x} \mathbf{4} \text { M) }\end{array}$} \\
\hline & $\begin{array}{r}\text { base }=2 ; \\
\text { bias }=1.1\end{array}$ & $\begin{array}{c}\text { base }=1 ; \\
\text { bias }=1.1\end{array}$ & $\begin{array}{c}\text { base }=0.5 \\
\text { bias }=1.1\end{array}$ & \begin{tabular}{|c|} 
base $=0.25$ \\
bias $=1.1$
\end{tabular} & $\begin{array}{c}\text { base }=0.1 \\
\text { bias }=1.1\end{array}$ \\
\hline well 86 & 13,615 & 12,566 & 11,581 & 10,765 & 9,834 \\
\hline well 87 & 16,118 & 13,85 & 12,193 & 11,137 & 9,912 \\
\hline well 88 & 16,729 & 14,155 & 12,537 & 11,425 & 10,173 \\
\hline well 89 & 11,592 & 10,914 & 10,111 & 9,476 & 8,715 \\
\hline well 90 & 16,767 & 14,304 & 12,584 & 11,453 & 10,166 \\
\hline well 91 & 15,681 & 14,135 & 12,786 & 11,69 & 10,51 \\
\hline $\begin{array}{l}\text { izmereni nivo u } \\
\text { mernoj tački (m.n.m.) }\end{array}$ & 89,33 & 89,81 & 90,07 & 90,33 & 90,59 \\
\hline
\end{tabular}

Cilj je svakako da se odabere odgovarajuća konfiguracija mreže koja će se dalje koristiti. U ovom konkretnom slučaju usvaja se računska mreža dimenzija računskih ćelija $4 \mathrm{mx} 4 \mathrm{~m}$, sa parametrima progušćenja Base size $=0.1$ i Bias=1.1.

\subsection{Uspostavljanje 3D numeričkog modela za nehomogenu sredinu}

Upotrebom softvera omogućeno je kreiranje modela $u$ kom su definisana dva sloja različitog geološkog sastava što je ovde slučaj kod stvarnog stanja na terenu. Kreiran je model strujanja koji karakteriše prirodno stanje strujanja u tlu. Potom su u model implementirani bunari, a mreža progušćena tako da se dobije usvojena računska mreža. I u ovoj fazi potrebno je da se dobije isti rezultat koji je i tražen projektom odnosno da nivo vode bude na min $1,0 \mathrm{~m}$ od površine terena

Za identični nivo u bunarima u ovakvom modelu dobijaju se znatno veći nivoi podzemnih voda. Stoga su daljom analizom rađeni modeli u kojima je nivo vode $u$ bunarima postepeno snižavan kako bi se dobila željena depresija.

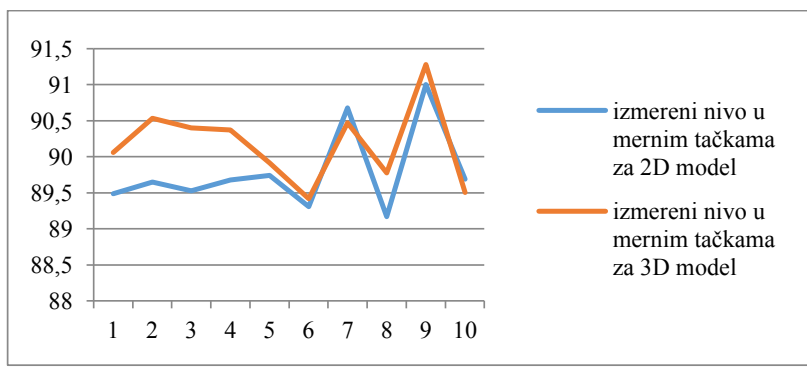

Slika 5. Razlika nivoa pijezokota za 2D model i $3 D$ model sa konstantnim nivoom u bunarima od 75,50 m.n.m.

Ustanovljeno je da model pokazuje svoj limit na koti 75,50 m.n.m. (treba naglasiti da je nivo podine na koti 72 m.n.m.) i svaki nivo ispod ovog dovodi do nestabilnosti modela.

S obzirom da se na ovaj način nisu mogli postići potrebni rezultati, sledećim korakom bunarima je zadat filtarski sloj. Model sa dva sloja i nesavršenom bušotinom jeste svakako stanje koje je najpribližnije realnom stanju na terenu. Da bi se filtarski sloj mogao uspešno modelirati mora se usvojiti više računskih ćelija po vertikali. Time će se modelirati i vertikalno strujanje, a samim tim i realnije stanje oko bunara. Izvedena su tri modela: sa 5,10 i 15 slojeva, uz zadržavanje definisanog nivoa u bunarima iz početnog modela (82m.n.m.) i adekvatne protoke dobijene ovom analizom. 


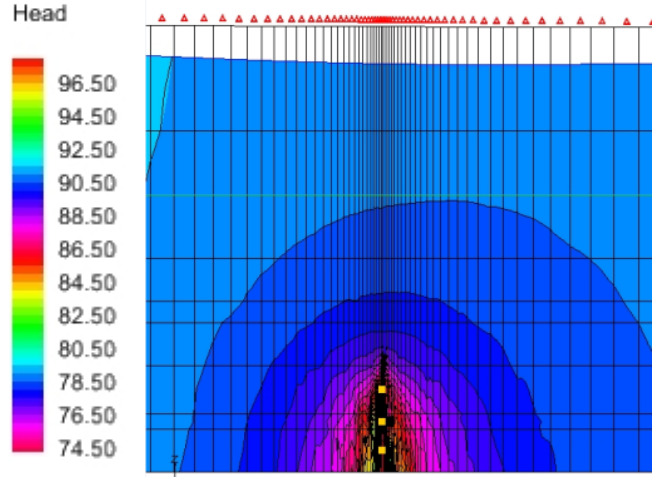

Slika 6. Prikaz strujne slike u zoni bunara sa filtarskim slojem za računski model sa progušćenjem u vertikalnom pravcu

Za ovakve protoke dobijaju se veći gradijenti uz bunar nego kod jednoslojne sredine čime se uzrokuju veće brzine što narušava stabilnost modela.

Za svaki od modela sa progušćenjem u vertikalnom pravcu sukcesivno su smanjivani protoci dok se ne dobije stanje strujne slike u kom su svi bunari aktivni i za koje se dobijaju najpovoljniji rezultati u smislu nivoa u mernim tačkama.

Rezultati su pokazali da model sa 10 slojeva ne zadovoljava uslov zadatka u pogledu traženog nivoa podzemne vode pa je iz tog razloga izveden je još jedan model u koji je uvršten dodatni bunar čime je obuhvaćena poslednja stavka zadatka master teze odnosno revizija i korekcija projektovanog stanja bunara dobijenih primenom 2D modela.

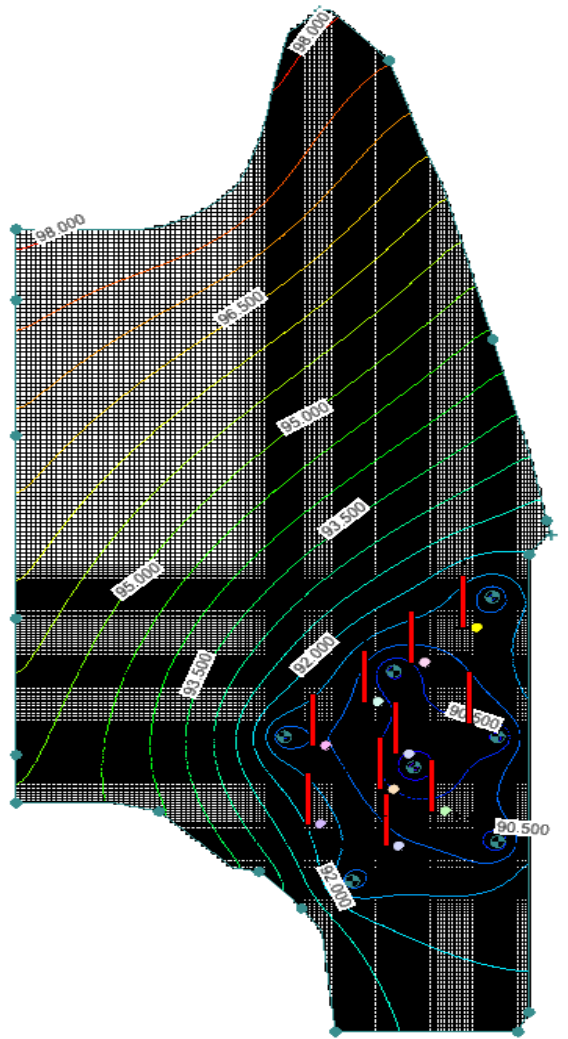

Slika 7. Prikaz nivoa pijezolinije za nehomogenu sredinu sa unetim položajem mernih tačaka i dodatnog bunara
Tabela 2. Poređenje dobijenih protoka na bunarima za složeni $3 D$ model sa protocima dobijenim rezultatima $2 D$ modela pri identičnom zadatom nivou

\begin{tabular}{|c|c|c|}
\hline $\begin{array}{c}\text { oznaka bunara (iz } \\
\text { modela) }\end{array}$ & $\begin{array}{c}\text { Zahtevavani protoci na } \\
\text { bunarima sa filtarskim } \\
\text { slojem i progušcenjem } \\
\text { mreže (10 slojeva) }\end{array}$ & $\begin{array}{c}\text { Zahtevani protoci } \\
\text { na bunarima } \\
\text { dobijeni 2D } \\
\text { modelom }\end{array}$ \\
\hline 86 & 5,93 & 15,02 \\
\hline 87 & 5,66 & 12,36 \\
\hline 88 & 5,6 & 18,45 \\
\hline 89 & 5,6 & 17,41 \\
\hline 90 & 5,65 & 18,1 \\
\hline 91 & 5,96 & 17,75 \\
\hline 490 & 5 & $/$ \\
\hline
\end{tabular}

\section{ZAKLjUČAK}

Kao rezultat celokupne analize dolazi se do zaključka da parametri kao što su gustina računske mreže i modeliranje bunara primenom filtra (realno stanje bušotina na terenu) bitno utiču na sam proračun. Shodno tome, ovaj tip analize je apsolutno neophodan kada se radi modeliranje strujanja podzemne vode. Analiza je pokazala da je predložen postupak privremenog snižavanja podzemne vode pomoću drenažnih bunara izvodljiv.

\section{LITERATURA}

[1] Lj. Budinski, Podzemne vode, predavanja sa master akademskog kursa na Fakultetu tehničkih nauka, Novi Sad

[2] N. Knežević, Snižavanje nivoa podzemne vode na gradilištu buduće fudbalske akademije u Bačkoj Topoli za vreme izvođenja pripremnih radova, Master rad, Fakultet tehničkih nauka, Novi Sad, 2017.

[3] Đ.Fabian, Lj.Budinski, Potpovršinske vode, Fakultet tehničkih nauka, Novi Sad, 2017.

[4] Pedološka karta Vojvodine razmere $\mathrm{R}=1: 100000$, Zavod za poljoprivredna istraživanja Novi Sad, 1958.

[5] Hidrogeološka karta Bačke razmere $\mathrm{R}=1: 200000$

[6] Geomehanički elaborat, AD „Zavod za geotehniku“ Subotica, 2016.

\section{Kratka biografija:}

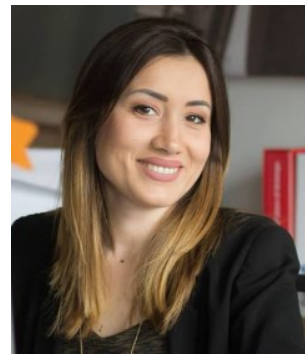

Marijana Dakić rođena je u Vrbasu 1990. god. Diplomski rad iz oblasti građevinarstvo - hidrotehnički objekti i sistemi odbranila je 2015. godine na Fakultetu tehničkih nauka u Novom Sadu. Master rad iz oblasti Hidraulika 2 - matematičko modeliranje obaranja nivoa podzemne vode primenom softverskog paketa GMS odbranila je na istom fakultetu 2018. godine.

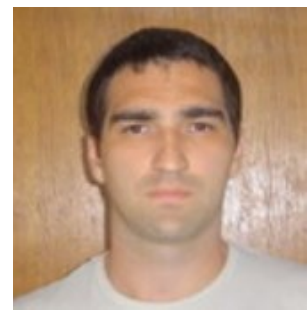

Ljubomir Budinski rođen je u Kuli 1976. godine. Doktorirao je na Građevinskom fakultetu u Subotici, a od 2017. godine ima zvanje vanrednog profesore na Fakultetu tehničkih nauka. Kao autor ili koautor objavio je 25 stručnih radova. 